\title{
Spectral Measurements of Pulse Solar Simulators
}

\section{T.W. Cannon}

National Renewable Energy Laboratory

Presented at the National Center for

Photovoltaics Program Review Meeting

Denver, Colorado

September 8-11, 1998

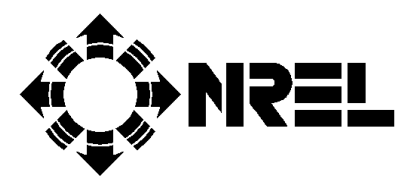

National Renewable Energy Laboratory 1617 Cole Boulevard

Golden, Colorado 80401-3393

A national laboratory of the U.S. Department of Energy Managed by Midwest Research Institute for the U.S. Department of Energy under contract No. DE-AC36-83CH10093

Work performed under task number PV907401

November 1998 


\begin{abstract}
NOTICE
This report was prepared as an account of work sponsored by an agency of the United States government. Neither the United States government nor any agency thereof, nor any of their employees, makes any warranty, express or implied, or assumes any legal liability or responsibility for the accuracy, completeness, or usefulness of any information, apparatus, product, or process disclosed, or represents that its use would not infringe privately owned rights. Reference herein to any specific commercial product, process, or service by trade name, trademark, manufacturer, or otherwise does not necessarily constitute or imply its endorsement, recommendation, or favoring by the United States government or any agency thereof. The views and opinions of authors expressed herein do not necessarily state or reflect those of the United States government or any agency thereof.
\end{abstract}

Available to DOE and DOE contractors from:

Office of Scientific and Technical Information (OSTI)

P.O. Box 62

Oak Ridge, TN 37831

Prices available by calling 423-576-8401

Available to the public from:

National Technical Information Service (NTIS)

U.S. Department of Commerce

5285 Port Royal Road

Springfield, VA 22161

703-605-6000 or 800-553-6847

or

DOE Information Bridge

http://www.doe.gov/bridge/home.html 


\title{
Spectral Measurements of Pulse Solar Simulators
}

\author{
Theodore W. Cannon \\ Center for Renewable Energy Resources \\ National Renewable Energy Laboratory (NREL) \\ 1617 Cole Blvd., MS 3411 \\ Golden, Colorado 80401
}

\begin{abstract}
Spectral measurements of pulse solar simulators are used to quantify the wavelengthdependant characteristics of the light. Because every PV device has a unique spectral response, it is important to know the spectral irradiance and to periodically monitor the spectra for changes. Measurements are made at the National Renewable Energy Laboratory (NREL) using several different techniques including the NREL-developed Pulse Analysis Spectroradiometer System (PASS).
\end{abstract}

\section{INTRODUCTION}

Solar device parameters are measured using pulse solar simulators. Pulse simulators are used in lieu of continuous simulators because much lower average power is required, and the device does not increase in temperature due to prolonged exposure to the light. The spectra are measured to determine simulator classifications (1), make spectral missmatch calculations (2), determine the spectral transmission characteristics of spectral-shaping filters, study the effect of lamp/filter changes and aging of the these components, determine the effect of spurious spectrally selective reflections within the test chamber, and determine spectral changes within the pulse period. These measurements require advanced techniques compared to measurement of continuous light sources; flashes are on the order of milliseconds long, so the instrument must be capable of capturing either an entire spectrum or of recording the spectrum one wavelength at a time within the period of one pulse. Most commercially available spectroradiometers are incapable of making these measurements. Several techniques that are used are described below.

\section{Bandpass Filter Technique}

An instrument called Spectracube was developed at the European Solar Test Installation (ESTI) (3) to measure both continuous and pulse spectra. This instrument consists of 64 independent detector modules, each with a field-of-view defining aperture tube (opening angle $2.98^{\circ}$, slope angle $1.04^{\circ}$ ), bandpass filter (bandwidth 10 to $100 \mathrm{~nm}$, depending on center wavelength), Si detector and shunt resistor. Data are digitized by two 12-bit A/D boards at $200 \mathrm{kS} / \mathrm{s}$. Spectracube is either calibrated outdoors using the sun as a source and comparing it against a conventional spectroradiometer, or by using an irradiance lamp standard. This instrument has the advantages of being capable of measuring time-resolved spectra (with about $5 \mu$ s time resolution) and measuring either pulse or continuous 
sources; it lacks the spectral resolution of a monochromator-type instrument and, as described in the article, is limited to the $422-1050-\mathrm{nm}$ wavelength region.

\section{Pulse Integration Spectroradiometer}

A commercial scanning spectroradiometer, the Optronic Laboratories model OL750 (4), is available with pulse integration capabilities. At each wavelength an external pulse from the light source triggers the instrument. Pulse integrating circuitry then measures the amount of charge developed by the detector during the flash. In a calibrated instrument, this charge is proportional to the pulse energy $\left(\mathrm{J} / \mathrm{m}^{2} / \mathrm{nm}\right)$ at each measured wavelength. This technique can be used with Si, PMT, Ge, or InGaAs detectors, so it can cover the wavelength range from the ultraviolet (UV) through near-infrared (NIR). This equipment has recently become available at NREL but has not been tested.

\section{Detector Array Instruments}

In this type of spectroradiometer, the light passes through an entrance slit, is dispersed by a grating monochromator, and is detected by an array of Si detectors. A typical detector array consists of 512 adjacent detector elements, each one responding to a narrow range of wavelength values. An amount of charge proportional to the time-averaged spectral irradiance over the bandpass of the detector is periodically dumped out of each diode to an A/D converter. This approach has the advantage of allowing the entire spectrum to be measured within hundreds of milliseconds.

Unless the readout of the array is time synchronized with the source, certain problems can occur. If the flash rate is higher than the integration time, the spectra can be erratic and skewed; if the flash rate is low compared to the integration time, it is virtually impossible to capture the data without excessive noise (the noise signal builds up throughout the integration period). If one or more order-sorting filters are not provided with this type of instrument, more than one measurement must be made; one without the filter and one with a long-pass filter with cut-on wavelength of about $600 \mathrm{~nm}$. A composite spectrum is then made from the two measurements. Array spectroradiometer applications for the measurement of pulse simulators are discussed elsewhere (5).

Measurements have been made at NREL using this type of instrument over the 350-1000$\mathrm{nm}$ region using an Analytical Spectral Devices FR spectroradiometer. This instrument has a bandwidth of $1.4 \mathrm{~nm}$ per detector element, and spectral resolution of $\sim 3 \mathrm{~nm}$ at 700 $\mathrm{nm}$. It incorporates an order-sorting filter as an integral part of the diode array. The shape of spectral line measurements can differ significantly from measurements using scanning instruments due to bandpass and slit-function considerations (see Figure 2.)

\section{Pulse Analysis Spectroradiometer System (PASS)}

This instrument was developed at NREL to measure NREL's Spire model SPI-240A and Spectrolab High-Intensity Pulse Solar Simulator (HIPSS) and Spectrolab Large-Area 
Pulse Solar Simulator (LAPSS). It is a scanning instrument, using an Optronic Laboratories model OL746D double monochromator with 5-nm bandpass using a Si detector over the 300-1100-nm wavelength region, and 20-nm bandpass using a Ge detector from 850 to $1800 \mathrm{~nm}$. Pulse energy can be measured either at one specific time during the pulse or by averaging over a specified region of time. Data acquisition is done automatically under computer control. Because the data are acquired one wavelength at a time, it can take several hours to do a scan when measuring the HIPSS and LAPSS simulators, which are limited to one pulse every two minutes. Pulse data at each wavelength can be saved to file to determine spectral changes within the pulse period.

\section{CALIBRATIONS}

The NREL instruments are calibrated against National Institute of Standards and Technology (NIST) spectral lamp standards (6) before each measurement. Calibration is necessary even if only relative (not absolute) spectra are to be measured because the spectral response of each instrument is wavelength-dependent. An internal optical chopper is used with the PASS to simulate light pulses of known irradiance. Considerable care must be taken to reduce scattered light and to establish orthagonality and distance between the lamp standard and reference plane of each instrument.

\section{SOME REPRESENTATIVE MEASUREMENTS}

Figures 1-5 show some measurements of the NREL Spire SPI-240A pulse simulator. Figure 1 shows measurements made using the NREL PASS and ASD FR instruments. These data were taken several years apart (1993 and 1998) and are used here only to illustrate the capabilities of the two instruments. The ratio of PASS to ASD measured spectra is shown in Figure 2.

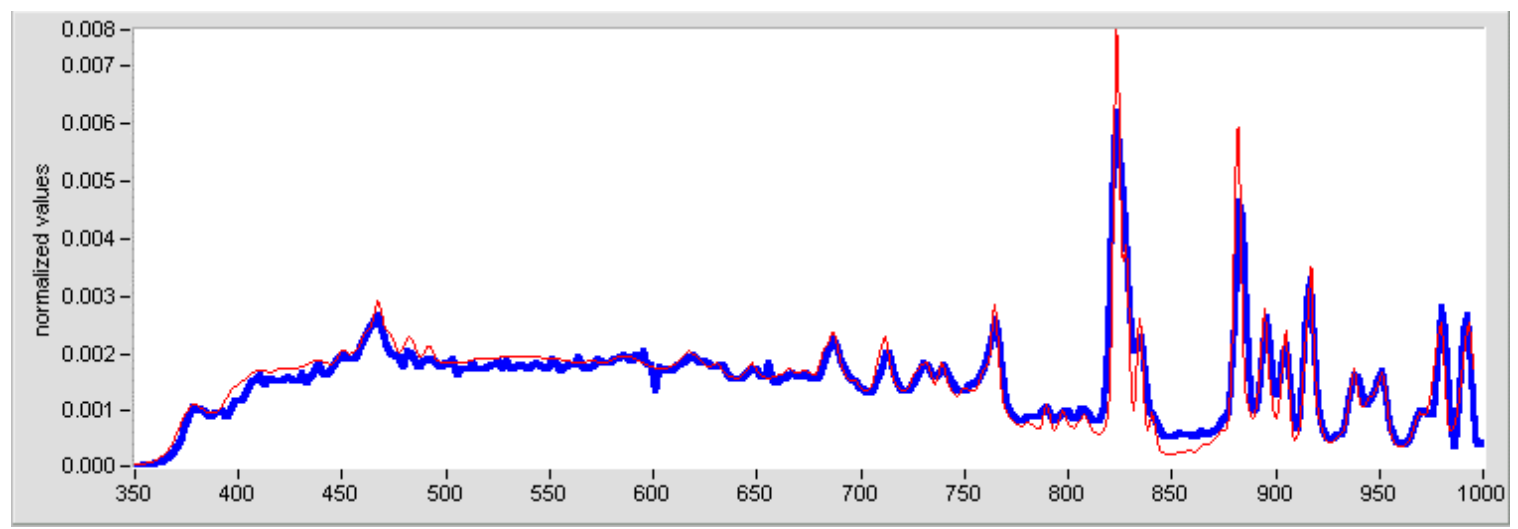

Figure 1. Measurements of a SPI-240A solar simulator using the PASS (thick line) and ASD (thin line). Data have been wavelength-calibrated at eleven Xe lines and normalized to unit area. 


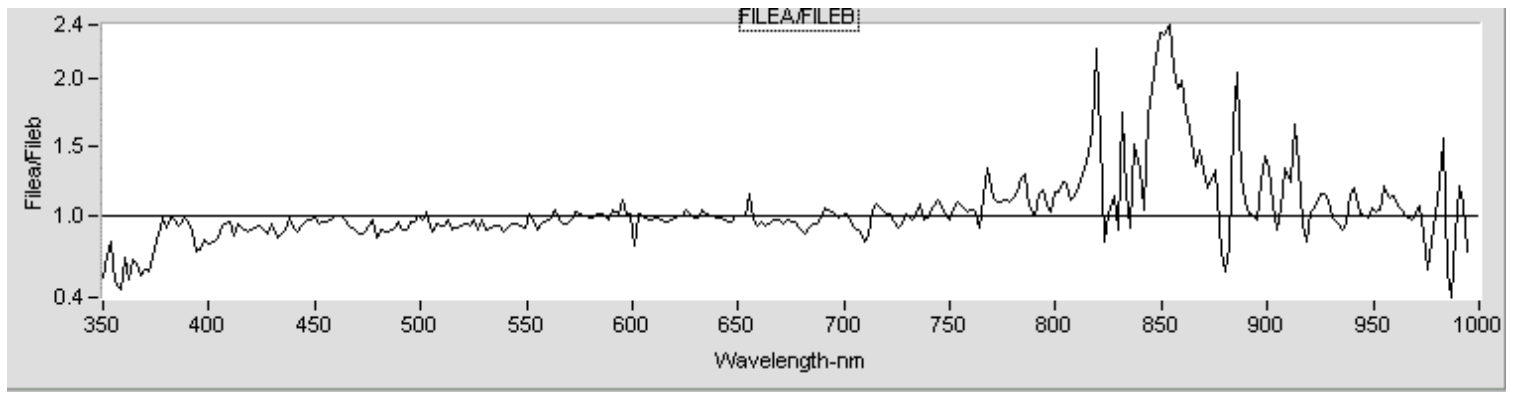

Figure 2. Ratio of the PASS to ASD measurements shown in Figure 1. Significant differences between the two measurements that are observed at spectral peaks are due to differences in bandpass and slit function of the two instruments.

Figure 3 shows the PASS data of Figure 1 and an ASTM E892 AM 1.5 global tilt standard spectrum (7). Histograms for these data are shown in Figure 4, and the ratio of the measurement to the reference spectrum is shown in Figure 5. The ASTM spectral limits for Class- A simulators are defined in ASTM E927 (1).

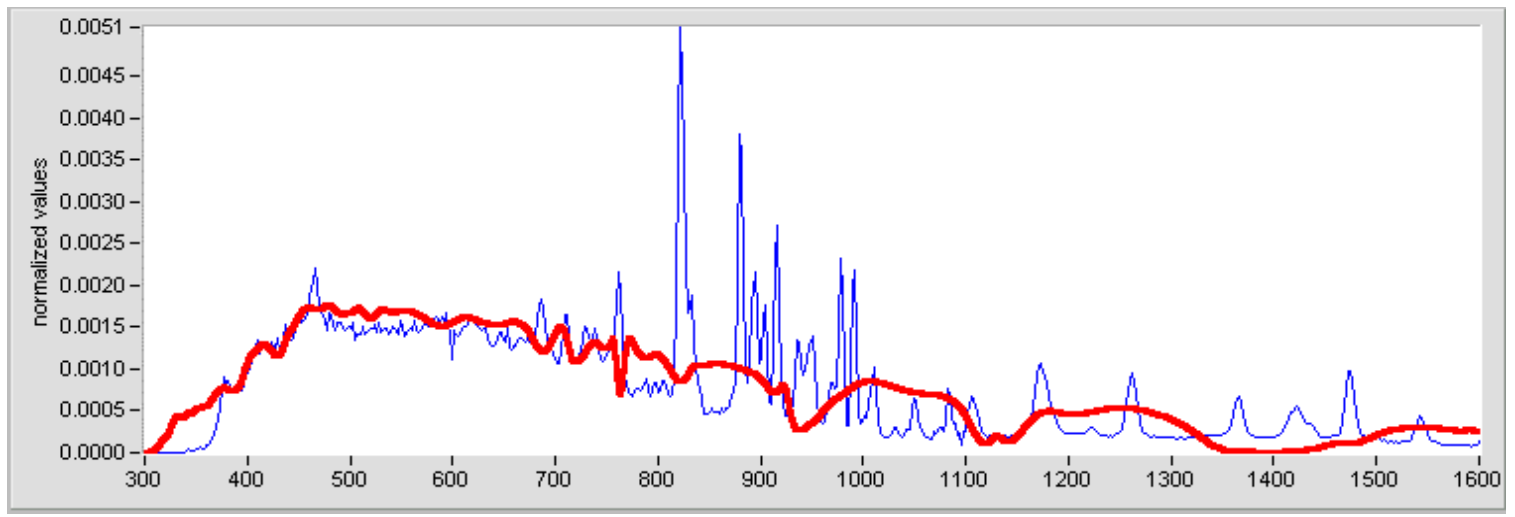

Figure 3. Area-normalized PASS measurement of the SPI-240A and ASTM E892 global tilt standard spectrum. Data are taken over the 300-1100-nm region using a Si detector, and over the 850-1600$\mathrm{nm}$ region using a Ge detector. All Ge data are adjusted to match the Si data within the overlap region $(850-1100 \mathrm{~nm}$.) The final composite file is made up of the Si data from 300 to $1100 \mathrm{~nm}$ and of the adjusted Ge data from 1100 to $1600 \mathrm{~nm}$. 


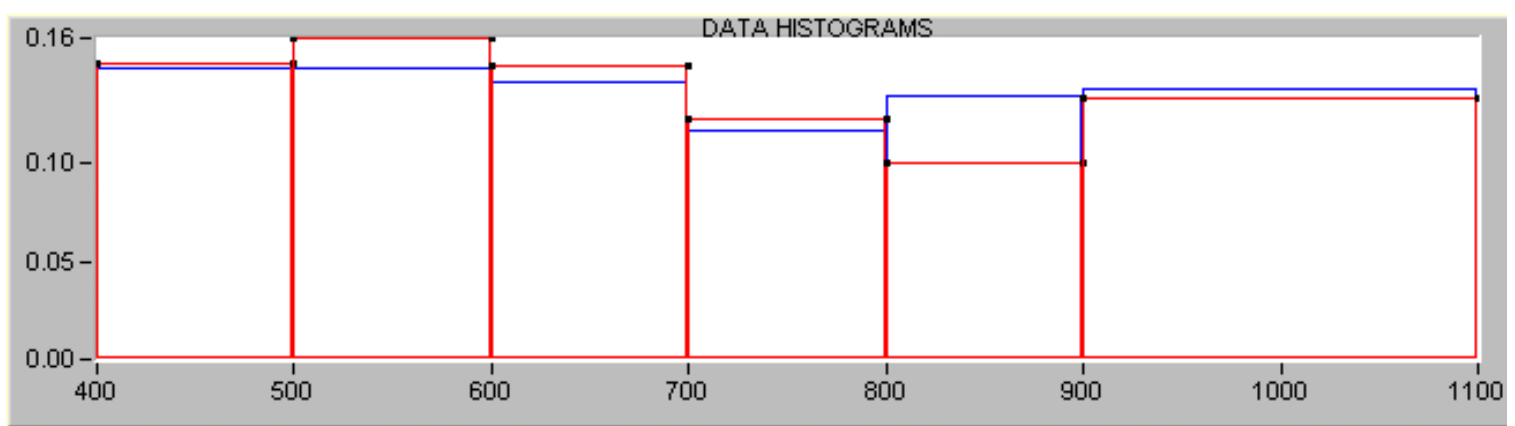

Figure 4. Histograms of data of Figure 3; dots demarcate the ASTM E892 data.

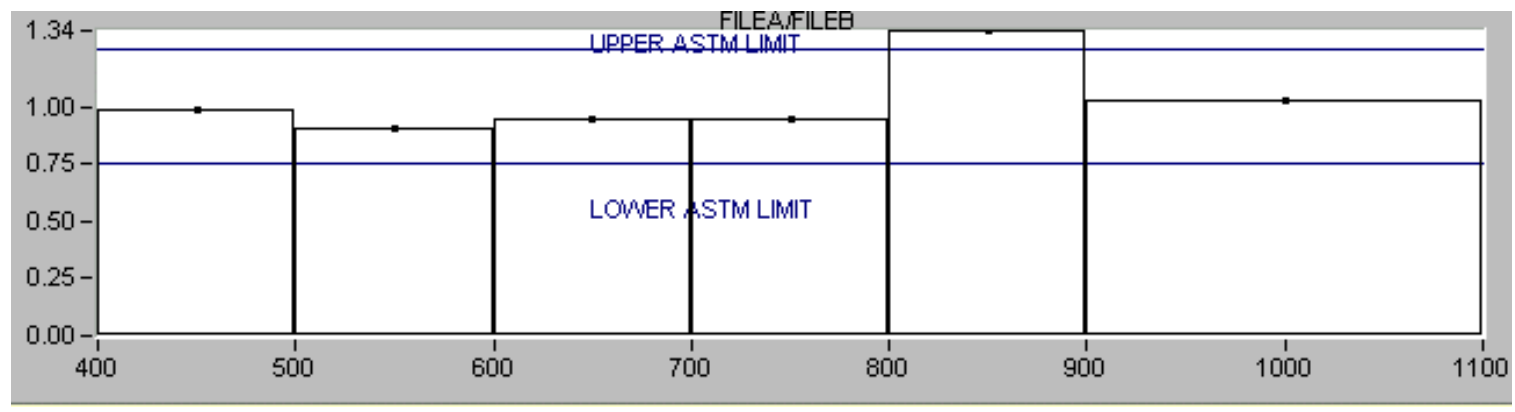

Figure 5. Ratio of PASS measurement to ASTM E892 with ASTM limits for Class A spectral mismatch specification limits.

\section{CONCLUSIONS}

Experience with various instruments and measurement techniques at NREL has shown that considerable finesse and effort are necessary to make accurate measurements of pulse solar simulators. The PASS is rather laborious and time-consuming, yet has produced the best results so far. Diode array instruments hold promise for more rapid spectral acquisition, but generally require time synchronization and special calibration techniques, especially if absolute spectral measurements are being made. Improvements in detector arrays, especially at wavelengths longer than the $\mathrm{Si}$ cutoff, should make these measurements more feasible in the future. Considerable work is being done on fast InGaAs arrays, which will extend the capability of array spectroradiometers to at least $2500 \mathrm{~nm}$.

\section{References}

(1) Anon., "Standard Specification for Solar Simulation for Terrestrial Photovoltaic Testing." ASTM E92791, 1994 Annual Book of ASTM Standards, Vol. 12.02. American Society for Testing and Materials, 1916 Race Street, Philadelphia, PA 19103.

(2) Anon., "Standard Practice for Determination of the Spectral Mismatch Parameter Between a Photovoltaic Device and a Photovoltaic Reference Cell,.” ASTM E972-83, 1987 Annual Book of ASTM 
Standards, Vol. 12.02. American Society for Testing and Materials, 1916 Race Street, Philadelphia, PA 19103.

(3) Zaaiman, W.J., H.A. Ossenbrink, and M. Martens, "Spectracube: A Fast Spectroradiometer for Pulsed Simulator Spectral Mismatch Corrections," 1994 IEEE First World Conference on Photovoltaic Energy Conversion, Conference Record of the Twenty-Fourth IEEE Photovoltaic Specialists Conference-1994, Volume 1, pp 877-879.

(4) Reference to commercial products in this article does not constitute an endorsement of those products by the author, the U.S. Department of Energy, or the National Renewable Energy Laboratory. Reference is for the purpose of illustration of commercially available, representative instruments.

(5) Myers, D.R. and T.W. Cannon, "PV Solar Radiometric Measurements", $14^{\text {th }}$ NREL/NSL Photovoltaics Program Review, AIP Conference Proceedings 394. American Institute of Physics, Woodbury, NY, 1996, p 395.

(6) Walker, J., R. D. Saunders, J. K. Jackson, and D.A. McSparron, "NBS Measurements Services: Spectral Irradiance Calibrations," NBS Publication SP250-20, 1987.

(7) Anon., "Standard for Terrestrial Solar Spectral Irradiance Tables at Air Mass 1.5 for a 37-Degree Tilted Surface." ASTM E892-87, 1997 Annual Book of ASTM Standards, Vol. 14.02. American Society for Testing and Materials, 1916 Race Street, Philadelphia, PA 19103. 